\title{
Study on the Changes of Marriage and Family Concept in the Period of Social Transformation
}

\author{
Yu Zhang \\ Ideological and Political Department, Anhui Sanlian University, Hefei 230001, Anhui province, \\ China
}

13499713@qq.com

Keywords: Social transformation period; Marriage and family concept; Mate; Love

\begin{abstract}
Marriage and family life is an important part of social life, the happiness or not will directly affect the level of personal well-being, but also affect people's evaluation of the individual's society. With the emergence of the social transformation period, the traditional concept of marriage and family in modern society has changed obviously. This paper carried out study on the reasons, development trend and the reconstruction of the correct marriage and family concept in order to provide a certain direction of guidance for the marriage and family of contemporary people.
\end{abstract}

\section{The Current Situation of Study on Contemporary Marriage and Family Concept}

Marriage and family theory formed at the end of the 19th century, it is established on the basis of sociology, a specialized subject focusing on contemporary people marriage and love value, derived from the psychology. The representatives is Burgess from British, Parsons from United States, John Gray and so on. The study of contemporary marriage is to investigate and study the family problems in the real world; the adaptation of the family to the modernity and the problems appear in the various stages of the family life cycle. And made great achievements, such as Parsons and Morton's functional analysis theory, Hormans's social exchange theory, Bruce's symbolic interaction theory. The study found that the family are established on the basis of marriage, and marriage is built on the basis of love. At that time, the family bear the population production and reproduction, holding the function of the organization of economic life and education function, its harmony or not, will affect the improvement of individual happiness to a large extent. After World War II, the problem has gradually been introduced into the country, the construction of a harmonious family has aroused the attention of the state and the specialists, but also cultivate and bring up a group of professionals, such as Li Yinhe, his masterpiece "Chinese marriage and happiness" " Chinese Marriage Family and its changes" " Dispute on the amendment of Marriage Law"; Chen Yijun, his masterpiece" Marriage and Family Science Consulting "'" Marriage and Family " " New Century Marriage and Sex "and so on. In the formation of the theory at the same time, but also they promote arising of the marriage and family counseling industry, their efforts, on the one hand, promote the field of theoretical progress, on the other hand, also save countless families in practice. April 2007, the National Ministry of Human Resources and Social Security approved and released the country's new career of "marriage and family counselors". It is the unique national certificate in the field of marriage and family counseling in China, which provide a more reliable theoretical and practical basis for promoting the execution of this work. Currently, our marriage counseling work carried out smoothly, the relevant departments will regularly organize annual marriage counseling, the 2018 New World Marriage and Family Conference will be held in Hangzhou, China, at that time, the specialists from the world of marriage counseling experts in the field will discuss the situation and development trends of marriage and family, which further illustrates China's great attention and achievements on on this issue. 


\section{Changes in the Marriage and Family Concept}

In the reality of research and practice, the author found that since ancient times, people hold different views on the marriage concept, in the Western Han Dynasty, Daide and Daisheng described marriage in the "Book of Rites. Marriage" as: "Marriage ceremony, combining with the different name for the good, on the matter of respecting the ancestor, and next to continue family, so the gentleman take care of it. "Means that the two people getting married, is knot two different family name for good relation, to be worthy of ancestors, then the extend family members, so people will be married are very cautious treatment about it. Since the founding of the People's Republic of China, the concepts of choosing mate, marriage or family have undergone great changes, especially with rapid development of China's market economy during the past 30 years, changes of people's marriage and family concepts triggered a series of family crisis, leading to social problems that can not be ignored, such as more and more single-parent families, juvenile problems, domestic violence, high divorce rate and so on, then these changes are mainly embodied in what aspects:

Firstly, in the spouse, the concept of young people have changed, the performance are more pragmatic. In the 1950 s and 1970 s, the standard of mate was family and political origin. In the 1980s, people were concerned about cultural and economic factors. Since the 1990s, there have been many factors in the standard of spouse choice, and some have even returned to love. In the new century, especially since 2010, many young people appeared the phenomenon of materialization in the spouse. Especially some of the older youth, they either missed the best season of love, or have experienced unforgettable love, but did not come together for various reasons, and finally only through the form of a blind companion to find spouse. So, some of the material things in the blind date will be placed on the table, such as the number of wages, several sets of house, these material conditions seemingly related to love is clearly marked to the price of marriage, while in the traditional sense, we think marriage should be based on love, at this time become insignificant. And even some people suggested that in the era of large data, we can match some young people according to large data, excellent selection from excellent, to choose the most suitable one for marriage by the regulation of object selection. This suggested point of view subvert the good expectations and longing to love of people, and everything will be measured on a realistic basis.

Secondly, the "perfect match" was again raised by many people. Of course, the "perfect match" referred by contemporary is no longer the traditional sense of the door to door, it was given a new meaning. For example, some people explain that "perfect match" not only refers to the material conditions, the family background, more emphasis on the level of the spirit with similar values, similar to the original family, etc., thinking that such a combination will reduce some friction in the future of marriage, because they have a good value base and similar role recognition.

Thirdly, in recent years, China's divorce rate has been high, and was increasing year by year. Even if no choice of divorce, but some people blatantly act extramarital affairs. "2015 Social Service Development Statistics Bulletin" shows that last year 3.841 million pairs handled divorce in the country according to the law, the crude divorce rate is $2.78 \%, 12$ consecutive increasing. the ratio of divorce to marriage $27.8 \%$, which means that every 4 pairs of people at the same time get marriage while there are 1 people divorced. Therein, the age mainly focus on the 30 to 35 years of age. From 2002 to the present, divorce rate become higher all the way. Chinese has a long tradition of family culture, while in recent decades, people are easily choosing to dissolve in the existing marriage, breaking the tradition of thousands of years, why? In the face of the emergence of more and more family crisis, the relevant departments in the future how to better guide people to re-build a healthy marriage and family view, how to better build a harmonious family, so as to build a harmonious society, worth thinking and researching.

Fourthly, the proportion of men who choose to remarry is much higher than that of women. A well-known dating agency person in charge did a survey, the relevant data show that: in 2014, a total of 844 divorced men came to the dating agency for registration, while only 121 for the divorced female, of which there are parents instead of daughter came to make their registration. 
China is a country with a long tradition of home culture, relying on the family and the emotional principle for women are far higher than the man. But the fact has changed, these men have suffered a marriage failure having a large proportion of the hope to achieve the reorganization of the family, but there are many women no longer choosing married again, this phenomenon subvert the tradition of China from ancient times.

Of course, in contemporary society, the awareness and changes on the concept of marriage and family are far more than mentioned examples above, here, we will no longer repeat them one by one.

\section{The Reasons for Changes in Marriage and Family Concept}

From the founding of country to the present, in a short period of 60 years of history, why young people's love and marriage concept changed so much?

First of all, in the mate selection, the mate selection is an important psychological, social and cultural phenomenon. As the most important choice in the life for the society members, the choice standard of mate and its model will undoubtedly reflect the value orientation of the whole society and culture. It is subject to a certain constraints of social history and culture, so that it companies with a certain social and the times. "Resource Exchange Theory" explained that people are attracted by a particular heterosexuality due to the resources he can provide, these resources come from many aspects, such as personal temperament, wealth, talent and social status and so on. Since the reform and opening up, with the development of market economy, people's thinking mode has undergone tremendous changes, the community is full of profit-oriented behavior, people will measure their own gains and losses in every choice in the event. While the change of the spouse standard also reflect this point. Young people in the process of choosing a spouse unconsciously embodies the theory of resource exchange, this resource may be their own characteristics such as their own qualifications, work, family conditions, beauty, etc., in the process of selecting mate, they want to use some of their own resources to exchange for the equal resources, and the best form of this materials are materialized everything, such as height and size, beautiful or not, the nature of work, salary geometry, real estate sets and so on. As for the difficult grasp of the abstract love, put behind by some people, they think that the conditions of these substances enough to replace the love hard to grasp.

Secondly, the "perfect match" concept are mentioned again, from a certain sense, it is the performance of social progress. Because it is no longer the traditional sense of the family origin, wealth, social status as the title should have the meaning. This concept is interpreted by more and more young people as the same experience, similar values and the roles of identity that both sides can accept. And these factors in the future marriage and family life, plays a decisive role in maintaining the stability of marriage. Psychologist B. Murstein argues that people need to go through three stages in the spouse selection, that is, the stage of stimulation, the value stage and the role stage. Successful mate selection must complete these three processes. While the implication of "perfect match" explained by contemporary young people contains these three aspects, it can solve the problems of future marital life escort, is conducive to maintaining the stability of marriage. Reduce conflict and friction, and conducive to the construction of harmonious gender relations. Because the combination of any couple is not a simple combination of men and women, but the combination of two houses and even two families, in the marriage life, the two sides will inevitably appear some differences and conflicts from different growth environment, as the core relationship between the couple, if the two sides can have roughly the same values and similar roles agreement, when the conflict occurs, they are often able to do things from the overall situation, understand each other, forgive each other, to maintain the stability of marriage.

Thirdly, since entering the new century, the reason why the high divorce rate appears is that it has a close relationship with China's economy in the transition period. Empirical research shows that China have been a high divorce rate in the fifties and sixties of last century, the main reason is that many women take the initiative to get rid of feudal society prompting their unfortunate marriage after entering the new society. But the generation after the founding of country, that is, 
married young people in seventies and eighties of century, their marriage is mostly arranged by parents, but because of the impact of the development of reality, their love out of marriage appeared, coupled with the impact of traditional concept, these people's happiness is not very strong, they put more experience on how to create more social wealth and improve life. After entering the new century, with the achievements of China's reform and opening up became more and more obvious, people in 80,90 of century gradually stepped into the marriage life, material living conditions for this generation were significantly improved, when the material life has been meet, they began to pay attention to their own happiness of life. Coupled with the emergence of various social trends, the temptation outside of the family made them rethink their own marriage. When the crisis appeared in the family, they do not know how to face, so choose to escape, and the best way to escape is divorce. And marriage has a large number of constraints also making modern men and women afraid of marriage, fear into marriage, into the family; married women who have entered the family, if found it is not suitable for each other, tied them together because of too many factors, no love or even no feelings of marriage is a torture for each other. This is also the main reason for the high divorce rate in China in recent years. In fact, divorce is not the fundamental way to solve the problem, if you do not change the original pattern of sexuality and marriage on the cognitive, the people who divorced even remarried are difficult to have a happy marriage. As to the emergence of extramarital affairs, it has a close relationship with the development of society, some people think with the improvement of that material conditions of life, it can take the opportunity to "enjoy" life; people do not understand the marriage life skills, when marriage problems appears, that extramarital affairs can be resolved between husband and wife. In fact, the phenomenon of extramarital affairs in China has seriously challenged China's monogamy, which is never allowed.

Finally, the reason why men after the divorce are willing to remarry was significantly higher than women, the main reasons are as follows: since ancient times, male is male species good at conquering all women. Men without wife are an important symbol of life failure, and they are better at doing work and action outside the family, that is, after the divorce, the vast majority of men want to find a wife as soon as possible to prove that he is not a loser, he can continue to conquer a woman; and they also want to find a person who can help them take care of the family, such as taking care of the elderly, cooking housework, caring for children, etc.; they also need a legitimate sex life; and these activities they can not complete alone, so after divorced, most of men will be eager to remarry, coupled with their very strong execution, that is, through a variety of ways to achieve their own goals, including blind date, the recommendation of acquaintances, free love and so on. As for divorced women, the reason why there will be a lot of people do not want to remarry are a lot, such as women are more emotional, they will take the road of divorce, the most of the situation is that men hurt her too deep, causing some women no longer believe in love; And now the society is the era of the rise of women, women are no longer needs to rely entirely on her husband in the economy as in the past, some of them can even have higher income than male, which provide a reliable protection for their divorced life, so they are not afraid of losing dependency, if the men as a spiritual are unreliable, they can choose to give up; and in the era of network services, in order to enhance the original family needs that male labor to provide, women can do it through a paid service to solve, some of them do not want to live with an incompetent husband just because of a few hundred dollars. All these reasons, resulting in that men are more eager to remarry than women after the divorce.

\section{The Reconstruction of a Healthy Marriage Concept}

Engels believes that with the economic development, the different times, regional differences, each era, every society, each place have different moral values, moral values of different classes are different, we can not use the same mechanical moral values to evaluate moral values and social system in different times, social, regional. Similarly, for the problems appearing in contemporary marriage and family, we can not equate with the traditional concept of marriage and family to evaluate the right or wrong, the key question is how to reconstruct the correct concept of marriage 
and family, which is today's society problem need to be solved, I believe that the problem should be resolved from the following aspects:

First of all, to follow the Western countries, provide pre-marital guidance for young men and women reaching the age of marriage, taking whether to participate in pre-marital guidance as a prerequisite for the formation of marriage, this guidance should include couple matching test, marriage analysis, providing scientific guidance for them to do spouse selection.

Second, the reconstruction of contemporary marriage and family concept. Society further promote the positive and healthy marriage and family concept, advocate family and tutor, the family also pay attention to their children's education, should increase the education of unmarried girls, strictly adhere to the marriage morality, to prevent them from breaking through the bottom line to become the sacrificial lamb of extramarital affairs. This requires parents to educate their children in the process of teaching and learning, and actively guide. And improve the relevant marital law, for marital derailed abandoned family members, once the evidence is conclusive, unless they get the forgiveness, otherwise they will get more serious punishment to increase the cost of divorce. It is also possible to provide necessary marital counseling before divorce, such as marriage counseling by marriage experts to analyze their marital problems, for saving those who can save the family, thereby reducing the divorce rate.

Finally, for those feelings have been broken, there is no possibility of marriage, divorce is also a correct choice. Society should also face this phenomenon, if the couple feelings have been indeed broken, reluctantly maintaining the marriage is not fair to both sides, because it limit their freedom to re-choose the spouse to some extent, nor in accordance with the law of divorce.

\section{Conclusion}

In short, in today's times, with the economic and social development and the continuous updates of concept, some changes of people's marriage and family concept in the contemporary society is the performance of social development, as long as people can face this change, to grasp the correct values in the change, harmonious and happy marriage or can be built up completely.

\section{Acknowledgements}

This paper is the key project of the Humanities and Social Sciences of Anhui Provincial Department of Education. Title: The Current Development Situation and Countermeasures of Folklore Communication Institutions Focusing on Chinese Ancient Civilization in Anhui Province. Subject No.: SK2015A636

\section{References:}

[1] (Western Han Dynasty) Dai De, Dai Sheng etc., Ritual [M]. Nanchang: Jiangxi Excellent Article Publishing House, 2012

[2] Yan Liping. Study the Western culture from the comparsion of Chinese and Western concept of marriage and family [J] Sichuan. Nanchong Read and Write Magazine, 2014, 10

[3] Li Cen, Xiong Liying Engels. Marriage and family concept [J] Economic Research Guide, Heilongjiang. Harbin, 2012.1

[4] Lu Jie, Wu Ning. Educational Sociology. [M] Beijing: People's Education Press, 2001: 522

[5] Jin Song, Huang Yongjun. Sociological analysis of male gender role differences in teaching [J] Education and Teaching Research, 2009 (9)

[6] (Australia) Malcolm Waters. Modern society theory [M]. Beijing: Huaxia Publishing House, 2000

[7] Li Xianlin. Some studies on the stereotype of gender roles [J] Psychological Dynamics, 1995, (4): 17-20

[8] Yan Yu. "Contemporary Chinese Marriage Ethics Evolution and Rational Orientation Research". Jilin Literature and History Publishing House 2009 
[9] "Selected Works of Marx and Engels" (Volume IV); People's Publishing House, 2009, p. 83

[10]Lawrence Stone. English family, sex and marriage [M]. Diao Xiaohua translated, Beijing: Commercial Press, 2011 